\title{
The Suicide Attempt in an Artificial Neural Network (Self Organizing
}

Map)

Keywords: Artificial neural network; Depression; Fatty acids; Linoleic acid; Platelet; Self organizing map; Suicide attempts

\begin{abstract}
In this paper, we have focused the position of subjects with suicidal ideation and suicide attempt, for psychiatric reasons, according to the platelet lipid fatty acids profile. A Self Organizing Map (SOM) has identified three fatty acids (Palmitic Acid [PA], Linoleic Acid [LA] and Arachidonic Acid [AA]), which have classified the major Mood Disorders (Major Depression and Bipolar Disorder), as described in previous reports. We have utilized the same self organizing map in a group of children obtaining results that can open a new way in the biochemical understanding of Mood Disorders in children.
\end{abstract}

\section{Introduction}

\section{Psychiatric disappointments and future appointments}

Worldviews, ideas, science projects, and existential scenarios, are never assets of the single individual, but a gift of community, to share with others.

The truth, in fact, as Lessing says, is not possession (Besitz), but research (Nachforschung), in which are embodied the efforts of individuals, aimed at we as a community.

This decade was marked by the review of the DSM, the fifth in the series, the instrument considered the "bible" of psychiatry, worldwide.

The document appears firmly rooted in traditional conservative psychiatry, ignoring the progress made by the biological research field. Clearly, the dichotomy between conservative and progressive psychiatry is not over, despite the efforts of the scientific research in the field of psychiatry, brain, neurotransmitters and quantum computation of the brain and consciousness, i.e., the disciplines that belong to neuroscience. It seems correct, from the ethic point of view, to remember how difficult it is to consider research in psychiatry as completely independent from influential external factors (kuhnian paradigms) [1].

Recently, some major events have paved the way for an innovative and deeply critical school of thought which started questioning the ideological implications of psychiatric diagnosis and the increasing complexity of the nuances in the classification of the psychiatric disorder. This movement supports, first, the idea of using biological markers in order to get a reliable diagnosis and appropriate care. This could limit the long-standing psychiatric error in the distinction between bipolar disorder and Major Depression [2], which ranges from $40 \%$ to $70 \%$ as stated during the Tenth World Day for the Prevention of Suicide, held in Rome (2012).

A number of authorities have criticized the fifth edition of the

\section{Journal of}

Neurology and Psychology

\section{Massimo Cocchi ${ }^{1,2^{\star}}$, Lucio Tonello ${ }^{1}$ and Fabio Gabrielli $^{1}$}

I "Paolo Sotgiu" Institute for Research in Quantitative \& Quantum Psychiatry and Cardiology, L.U.de.S. University, Switzerland ${ }^{2}$ Department of Veterinary Medical Sciences, University of Bologna, Italy

*Address for Correspondence

Massimo Cocchi, "Paolo Sotgiu" Institute for Research in Quantitative \& Quantum Psychiatry \& Cardiology, L.U.de.S. University, 103, Palazzo Pietro Stiges, Strait Street, Valletta VLT 1436, Switzerland, E-mail: massimo.cocchi@unibo.it

Submission: 31 October, 2016

Accepted: 25 November, 2016

Published: 30 November, 2016

Copyright: () 2016 Cocchi M, et al. This is an open access article distributed under the Creative Commons Attribution License, which permits unrestricted use, distribution, and reproduction in any medium, provided the original work is properly cited.

DSM, even before its official publication. The main thrust of criticism has been that changes in the DSM have not kept pace with advances in scientific understanding of psychiatric dysfunction. Another criticism is that the development of DSM-5 was unduly influenced by input from the psychiatric drug industry. A number of scientists have objected that the DSM forces clinicians to make distinctions that don't have solid evidence, distinctions that involve implications of pharmacological treatment, including drug prescriptions and the availability of health insurance coverage.

From an anthropological point of view, we can consider the human being as the condensation between Körper and Leib: the lived experience is always rooted in the biological aspect; phenomenological losibility and impossibilities are also, and first, biological losibility and impossibilities.

To keep on stating the difference-often denied only in intentionsbetween erklaran (causal explanation) and verstehen (psychological comprehension) means ignoring the productive acquisition of complexity theories; it means being trapped in the "myth of sense" when hypostatizing those lived experiences, phenomenological approaches and philosophical thoughts from which a genuine interpretation of psychopathology should be derived.

Hence, the need for a gestalt reorientation: biology too, generates sense. In fact, it is the original sense on which other forms of sense can develop and it strongly interacts with philosophy and other types of knowledge (biochemistry, quantum physics, biomathematics, anthropology, sociology etc.), in the perspective of a comprehensive and heuristic unity, as the symbol of a psychiatry able of mature and independent conceptual reworking.

The Scientific Community and the clinical world must make further efforts to turn psychiatry into a bio-analytical-existential heuristic set of knowledge, so that diagnosis will not be anymore enslaved to the Heidegger's yoke of ideas (classification ideology and 


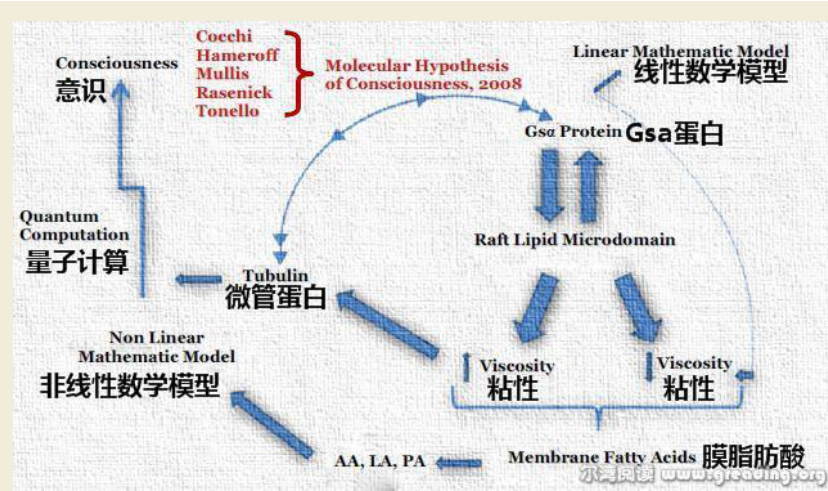

Figure 1: Molecular Hypothesis of Consciousness.

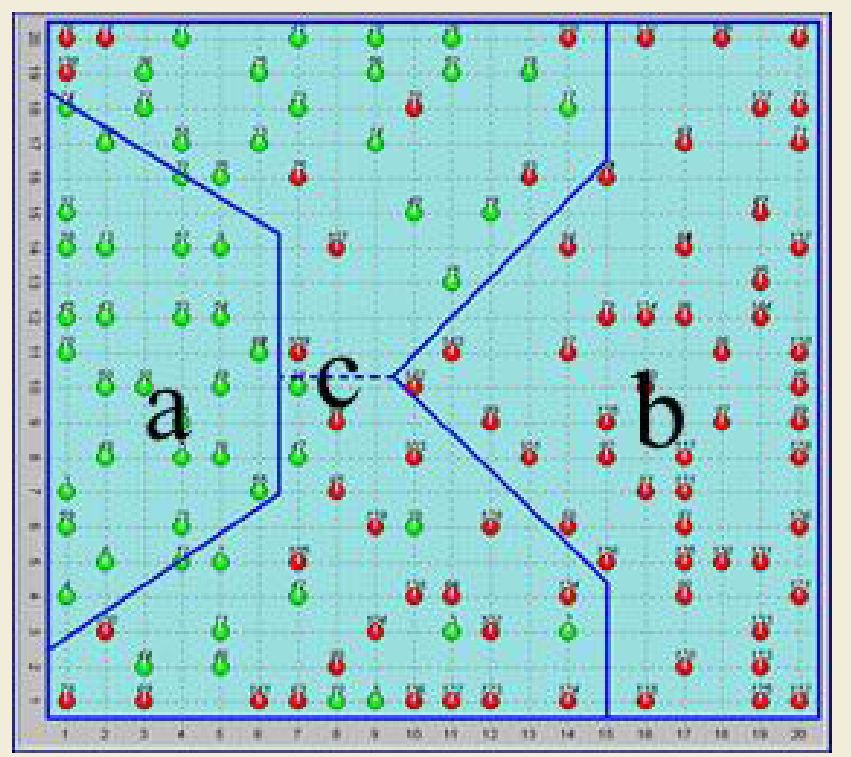

Figure 2: Distribution of all cases of the first experiment. The distribution of normal and pathologic cases over the SOM.

diagnostic imperialism) but rather be guided by cogent biological markers [3]

In brief, biology is the starting point towards more and more complex systems, capable of combining biochemical expressions, irreducible existential experiences, social and cultural backgrounds.

Therefore, depression must be set in an un-mythicized, indefinite horizon where biological, physiological, clinical, existential, psychosocial, and anthropological-cultural elements can insert in the most objective hermeneutic framework possible.

In other words, micro-foundation-that is to say the fact of bringing back macro-levels to micro-explanations-with all its constructions and laws, does not have to pave the pay for an eliminative reductionism but rather lead to an open and pluralistic inclusionism. The pluralistic inclusionism where it counts only the micro molecular evidence, whereas everything that is macro, from the biological level to the cognitive and socio-cultural ones, is just an epiphenomenon, a trivial incident.

Anyway, inclusionism must avoid potential anti-psycho- pharmacological implosions arguing that drugs are just instruments to control and stabilize psychotic bouts [4].

Actually, it could be easy to degenerate into a pseudophenomenological rhetoric, on the base of merely observational studies, and put the emphasis on the side effects of psychoactive drugs, (as if the other medications would not have any). It should not be forget that the number of diagnosable mental disorders went from 100 in 1952, to about 300 today, along with all the related diagnostic and therapeutic issues.

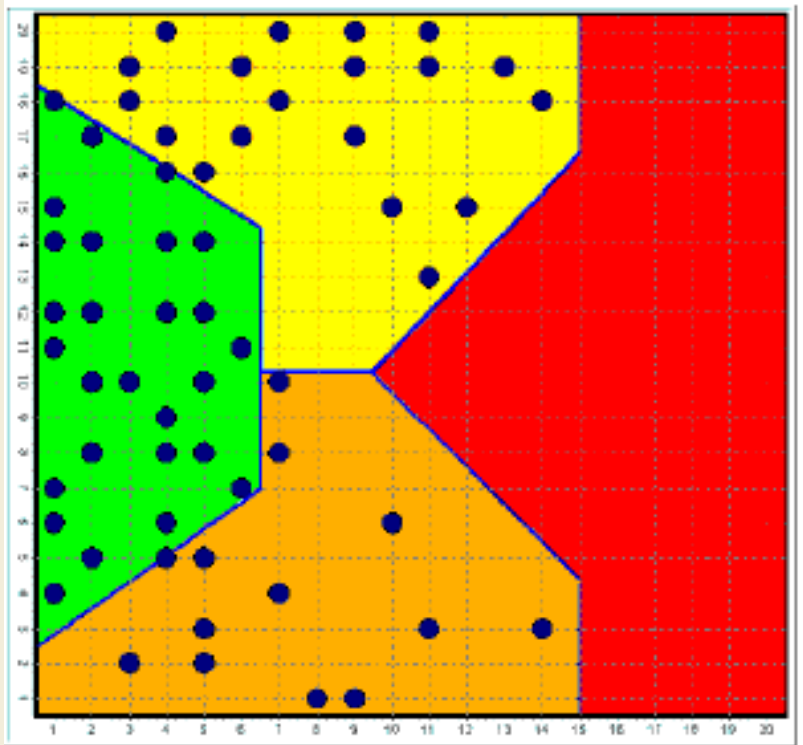

Figure 3: Distribution of normal subjects over the SOM. The group has been clustered to better show the distribution.

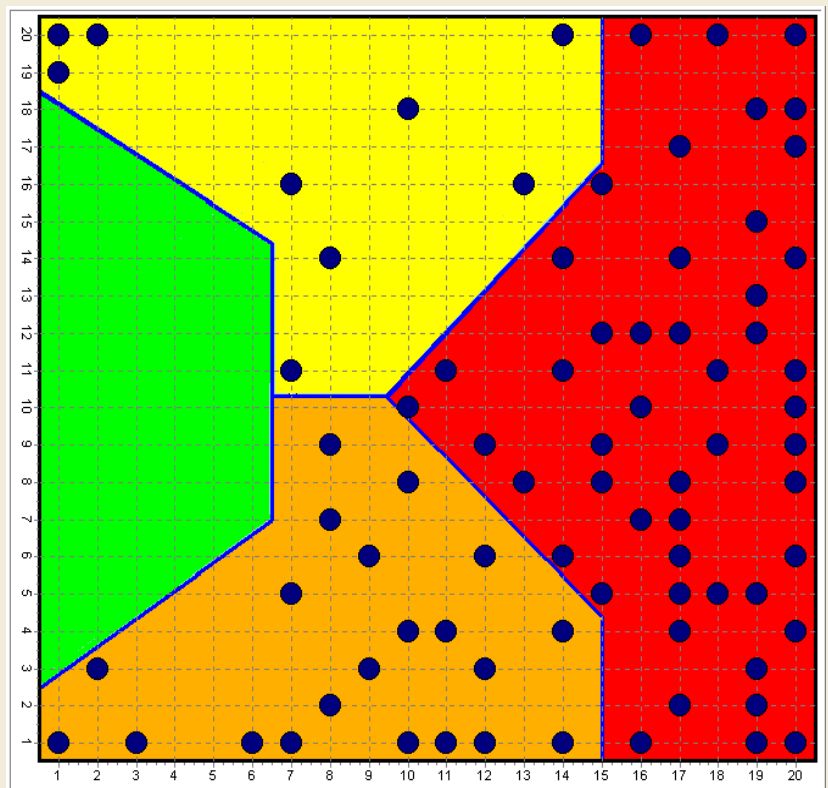

Figure 4: Distribution of depressive subjects over the SOM. The group has been clustered to better show the distribution. 


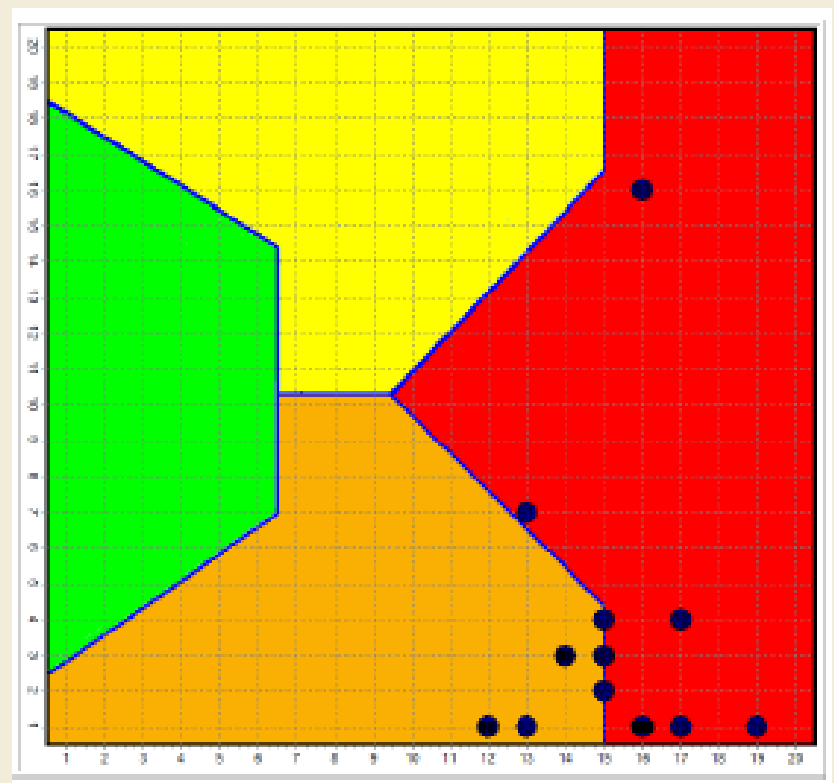

Figure 5: Distribution of the MD and BD subjects over the SOM.

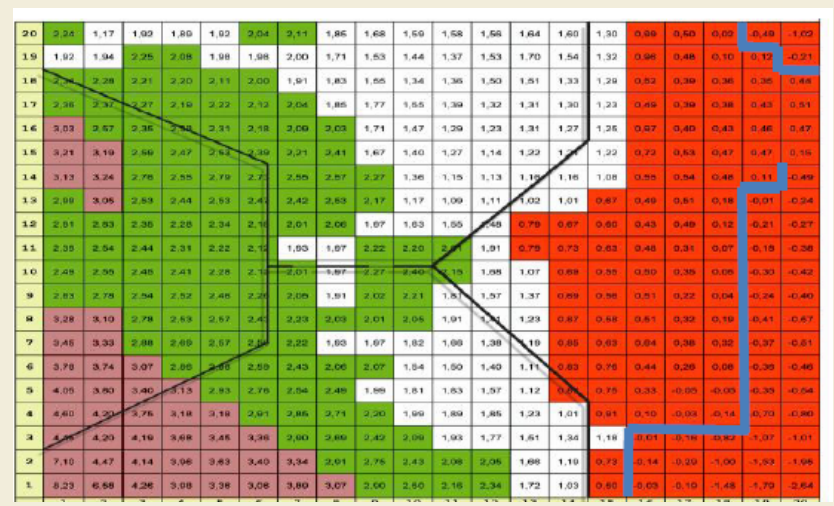

Figure 6: Distribution of the B2 index and overlapped the SOM clusters (dark lines). The blue line delimits the negative indexes (MD).

We must remember that uncontrolled marketing operations, and convenient as well as unethical psychiatric solutions, weigh on psychopharmacology: that is the reason why psychiatry needs clear biological correlates for psychopathologies in order to create a concise, clear, efficient psychopharmacology free from over diagnostic deviations.

The World Health Organization (WHO) continues to spread alarming data on the incidence of suicides, which, among young people, are one of the leading causes of death. In addition, claims that the growth forecasts of the phenomenon would place the depressive, along with cardiovascular problems, including the most common and worrying diseases in the world.

A percentage of $40 \%$ or even $70 \%$ in certain cases of misdiagnosis is really a disconcerting data, since it means that a multitude of people has to deal with very serious therapeutic problems and if treatment is wrong, not only the subject undergoes devastating situations, but also increases the risk of suicide.
Beyond the conviction that major depression can found its origin in genetics [5-7], a bio molecular mechanism could be hypothesized from what emerged from the studies on platelets fatty acid composition in human (normal and depressive subjects). This allowed classifying the depressive disorder from the bipolar disorder using an Artificial Neural Network (Self Organizing Map-SOM), as mathematical tool, because of the complexity of the membrane dynamics [8-14].

Rapid changes in membrane lipid composition or in the cytoskeleton could modify neuronal signaling. In the knowledge to have found something that could have implications in the understanding of some aspects of psychiatric disorders and a very suggestive hypothesis was build as summarized in Figure 1. In Figure 1 is described the molecular depression hypothesis made according to Cocchi and collegues, Donati and collegues, Hameroff and Penrose $[8,9,15-17]$. The membrane viscosity can modify the Gsa protein status. The Gsa protein is connected with Tubulin. Tubulin, depending on local membrane lipid fase concentration, may serve as a positive or negative regulator of Phosphatidylinositol Bisphosphate (PIP2) hydrolysis, such as Gsa protein does. Tubulin forms high-affinity complexes with certain $\mathrm{G}$ proteins. The formation of such complexes allows tubulin to activate Gsa, which, in turn, can activate the Protein Kinase $\mathrm{C}$ and fosters a system whereby elements of the cytoskeleton can influence $\mathrm{G}$ protein signaling. Rapid changes in membrane lipid composition or in the cytoskeleton might modify neuronal signaling. We have hypothesized that through this

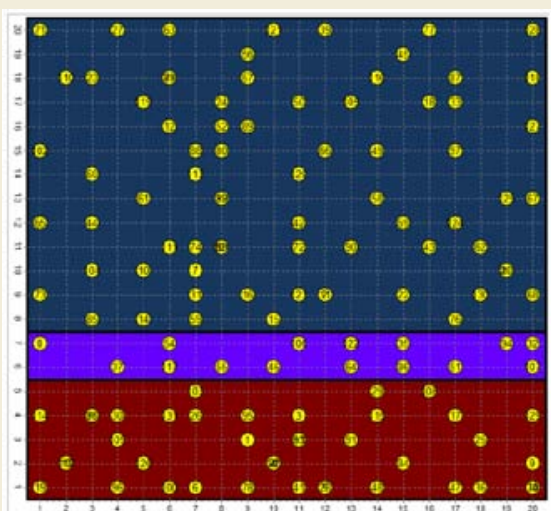

Figure 7: The new SOM (Abel) recognize the MD (brown area) and the BD (blue area).

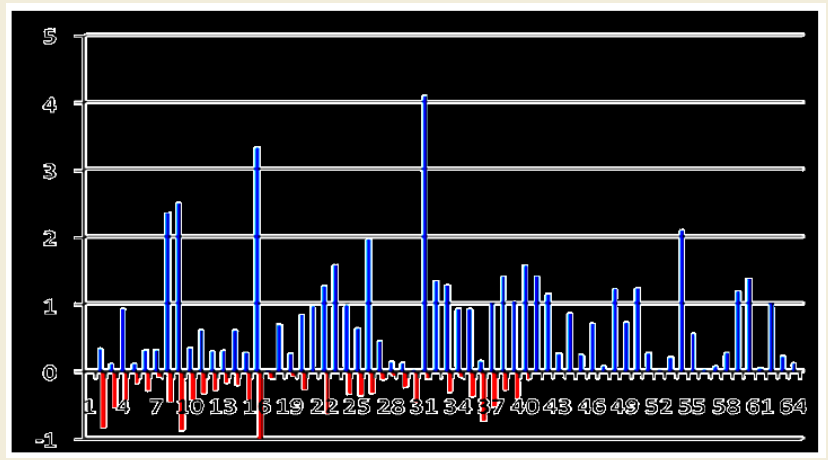

Figure 8: Histogram of the $\mathrm{B} 2$ index (Blue=BD and Red=MD). 


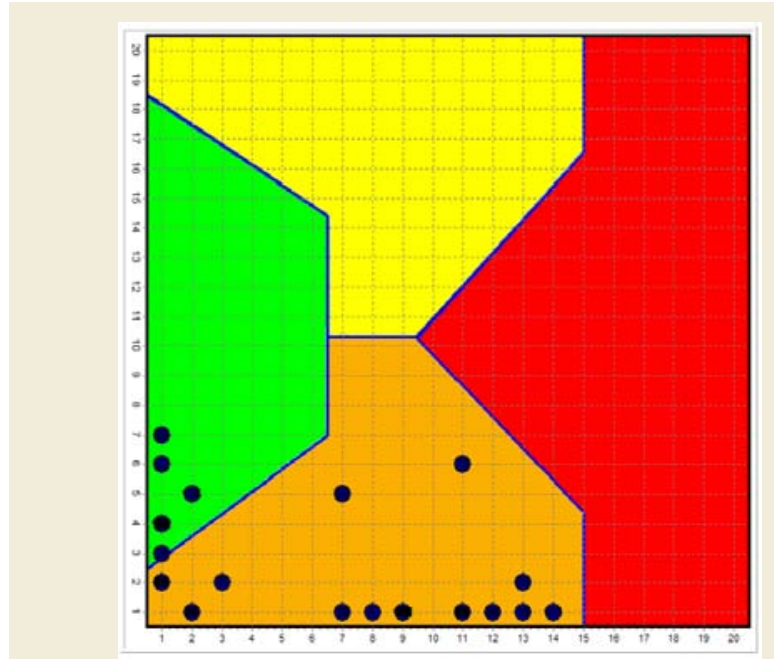

Figure 9: Distribution of all children's fatty acid triplets over the SOM.

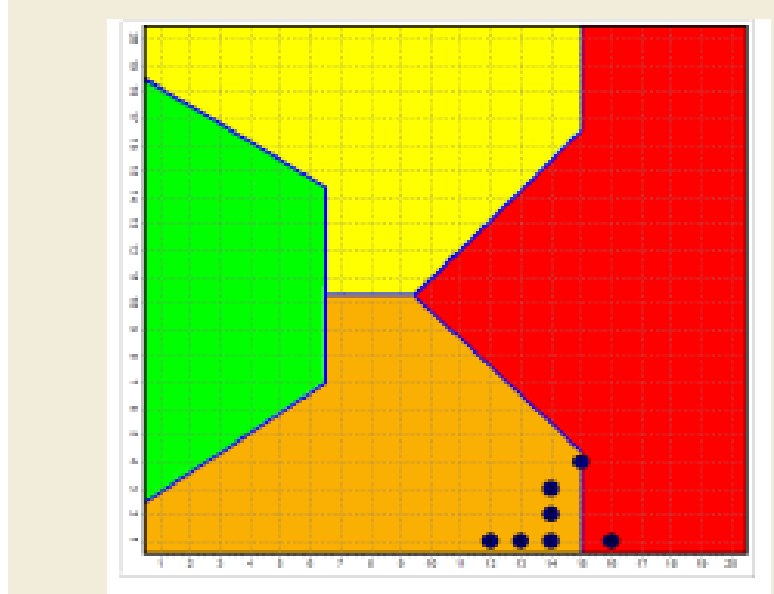

Figure 10: Distribution of all "adult suicide" together with children.

mechanism is possible to modify the consciousness state and that it is measurable through gamma synchrony EEG [18].

There are strong reasons to think that platelet' PA, LA and AA, are responsible of the membrane viscosity being the majority of the full platelet' fatty acids profile [19]. Further, they can condition molecular and cellular structures (Gsa and Tubulin) and the main therapeutic target is to restore a proper balance of membrane viscosity.

A project on quantum and molecular aspects of psychopathology is in the planning stage. The project involves the participation of internationally renowned scientists (Gustav Bernroider, Massimo Cocchi, Lucio Tonello, Fabio Gabrielli, Mark Rasenick, Jack Tuszynski, Donald Mender, Massimo Pregnolato, and Francesco Cappello) and refers to the Nobel Laureate Kary Mullis.

The research named "Quantum Neuron Molecular Mapping Project" (Q-NeMoMa), aims to achieve the objective of verifying the molecular modifications of neuron (Cytoskeleton, Gsa protein, Ion Channels) in terms of different levels of viscosity of the membrane, corresponding to the conditions which characterize the two psychopathologies of greater diffusion in the world: Major Depression and Bipolar Disorder. From this important research it will be possible to obtain data needed to assess whether it will be possible a corrective action for the improvement of the devastating conditions of all those who are suffering from mood disorders and changes of consciousness. Since it is well known that Gsa protein and tubulin have a connexion it seems reasonable to raise the question of a possible link to consciousness according to Hameroff-Penrose Orch. theory. The results will have practical use and be of great interest in more than one scientific field of application e.g. in the study of new drugs for psychiatric disorders and in the diagnostic evaluation of depressive disorders.

\section{Research in Brief}

The research proceeded through different stages, as can be seen below.

First stage of the research (Background): Platelet fatty acids results obtained from apparently normal subjects and from subjects generically classified with Mood Disorders (classic psychiatric

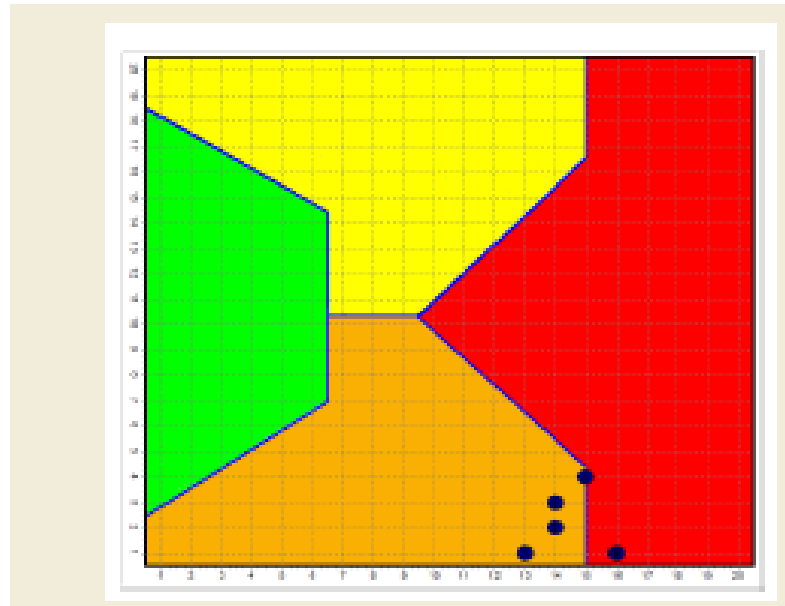

Figure 11: Distribution of "adult suicide" over the SOM.

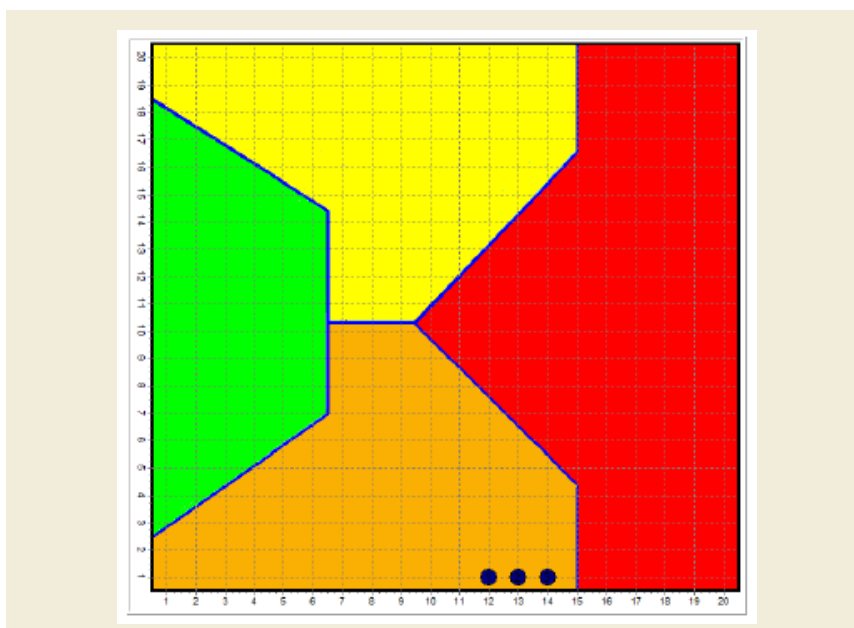

Figure 12: Distribution of children with similar molecular characteristics to "adult suicide" over the SOM. 


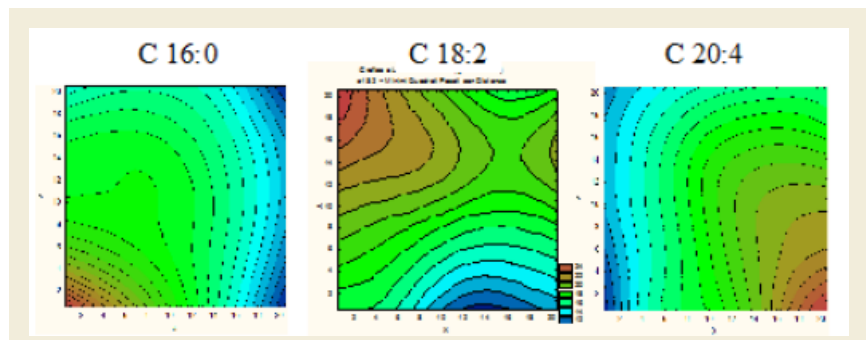

Figure 13: Level curve of PA, LA, AA over the SOM. The picture show the level of $L A(C 18: 2)$ in a level curve representation. Higher levels of LA are brown coloured; middle levels are green while lower levels are blue. The socalled "suicide" area corresponds to the minimum value of LA. Is C18:2, the main actor of "the fine tuning"?

diagnosis) were analyzed through the use of a Self Organizing Map (SOM), as described in previous reports [8,9] [Figures 2-4].

In previous research, the quantitative molecular aspects of human depression have been explained [10].

Figure 2 shows the map clusters (normal and mood disorders) on the SOM: three main areas have been obtained:

a. Normal subjects area (a-only green dots)

b. Depressive and Bipolar subjects area (b-only red dots)

c. Mixture of both (c-red and green dots)

The third area was split into two other areas (yellow and orange) according to the major density of normal (yellow) and pathological (orange) subjects [8].

\section{Second stage of the research}

\section{Materials and Methods}

For the experimental purpose, we have investigated 105 adult subjects and 112 children:

\section{Adult subjects}

Inclusion criteria: All subjects had been diagnosed with Bipolar Affective Disorder (BD) or Major Depression (MD). Diagnosis is reached through a survey clinical-anamnestic time to ascertain the presence of the criteria specified by DSM-IVTR.

All patients underwent psycho diagnostic investigation: HRSD21, HRSA, CGI, SCL-90, and HCL-32. The subjects were recruited without regard to sex, age, food intake patterns, or pharmacological therapies.

The study was double blind.

Exclusion criteria: Subjects who did not give consent, patients

For the experimental purpose, we have investigated 105 adult subjects and 112 children:

\begin{tabular}{|c|c|c|}
\hline Adult & Depressed (MD) & Bipolar (BD) \\
\hline $\begin{array}{c}\mathrm{n}=105(\mathrm{f}=71[68 \%], \\
\mathrm{m}=34[32 \%]) \text { age: } 50.3 \\
\pm 13.7\end{array}$ & $\mathrm{n}=40(\mathrm{f}=28[70 \%], \mathrm{m}=12$ & $\mathrm{n}=65(\mathrm{f}=43[66 \%], \mathrm{m}=22$ \\
$[30 \%])$ age: $50.5 \pm 14.7$ & $[34 \%])$ age: $50.2 \pm 13.1$ \\
\hline Children & \multicolumn{2}{|c|}{} \\
\hline $\mathrm{n}=112$ age: $10.5 \pm 2.7$ & \multicolumn{2}{|c|}{ No psychiatric assessment } \\
\hline
\end{tabular}

with a diagnosis other than an affective disorder and persons in their first clinical episode.

\section{Children}

112 children (age $10.5 \pm$ SD 2.7) were recruited without considering any factor but their age. In particular, mood disorders were not tested for.

Both studies were carried out according to the Declaration of Helsinki. The parents of the subjects were given details of the study and they gave informed consent. The local research ethics committee approved the study.

Blood sampling: Blood samples $(10 \mathrm{ml})$ from patients were drawn from the ante cubital vein. In all cases, blood was anti coagulated with EDTA (vacutainer, England). Platelets were prepared essentially as described by Iida et al. [19]. Briefly, Platelet Rich Plasma (PRP) was prepared by centrifugation of blood.

Quantization of fatty acid patterns of platelet pellet was performed by Gas chromatography-mass spectrometry-GC-MS [9].

\section{Mathematical method}

Self-organizing map (SOM): Teuvo Kohonen created the SOM as an unsupervised competitive-learning network algorithm [20-22]. The central property of the SOM performed in the current paper is that it forms a nonlinear projection of a 3-dimensional data manifold on a regular, $2 \mathrm{D}$ grid. The data items are vectors, the components of which are the amount of AP, AL and AA, of each subject. The SOM grid can be used as a groundwork on which each of the vectors can be displayed separately. This kind of combined display has been found very useful for the understanding of the mutual dependencies between the variables, as well as of the structures of the data set. In the context of this definition, a manifold refers to a topological space with welldefined mathematical properties. In the display, the clustering of the data space as well as the metric-topological relations of the data items, are clearly visible. A particular strength of the SOM displays lies in enabling relevant information to be 'found' rather than 'searched for'.

B2 Index: The B2 index was obtained from the summation of the percentages of each fatty acid (selected by SOM) multiplied by its melting point and divided by its molecular weight, obtaining an indirect expression of membrane viscosity, which induces to identify it with the neuron membrane viscosity, as described by Cocchi et al. [23].

\section{Results}

\section{Adult subjects}

Using the combination of the SOM and of the $\mathrm{B} 2$ index gave the following results (Figures 5-7). MD and BD subjects were recognized not only from their position over the SOM but also by way of the B2 index (negative in MD and positive in $\mathrm{BD}$ ) [13].

A new SOM has been made to verify if the same triplet of fatty acids was able to confirm the separation between $\mathrm{MD}$ and $\mathrm{BD}$, thus enabling its use for future diagnostic classifications.

The result is showed in and has been compared with the histogram of the $\mathrm{B} 2$ index to verify the correspondence (Figures 7 and 8). 
The purple area shows the borderline subjects, i.e., with positive and negative indexes in a narrow range and which, however, correspond to the depressed and bipolar subjects as recognized by the $\mathrm{B} 2$ index.

\section{Children}

Using the same method, we distributed the platelet fatty acids triplets of a group of children over the original SOM (Figure 9).

We can observe that none of the children is in the red area. Because all the subjects with Major Depression are placed in a specific part of the red area (Figure 6), we concluded that it was not possible to attribute to any of the children studied, the condition of major depression. Perhaps the condition of Major Depression is very rare among children.

\section{SOM and "suicide" thoughts and attempts: results}

From the adult subjects of the experiment, 8 patients with "suicide attempt" (psychiatric diagnosis) have been clustered over the SOM and compared to children with the same platelets' molecular characteristic of the "adult suicide" (Figures 10-12).

As it is possible to see in Figure 10, the "adult suicides" (7 bipolar, 1 major depression) range between the position 13 and 16 of the abscissa clearly forming a cluster. We have identified this area as a cluster of "suicides". Because of the precision of the SOM, it seems excluded the position 12 for the children, so, the children really corresponding to the "adult suicide" position are 2.

We tried to study the "suicide area" of the SOM in order to find common feature among people with suicide thought or attempt, according to the SOM itself. We have focused our attention at the level of the three Fatty Acid and found that the "suicide area" of the SOM corresponds to the lowest value of the LA, which seems the critical aspect in "suicide", as showed in Figure 13.

\section{Discussion}

The degree of platelet cell membrane viscosity (the mirror neuron) is an element that allows the possibility to distinguish bipolar subjects from major depressive subjects, as factor independent from therapy, age, gender etc. [13]. The state of the platelet membrane, and the fatty acid profile which affect the viscosity, therefore, become a determining factor for understanding not only the condition of the subject but also the amount of serotonin uptake [13], thus discriminating the power of the therapeutic intervention. Attention must be paid to the very young subjects because of their low cholesterol membrane concentration, which makes more fluid the membranes also if the membrane itself tries to compensate this condition raising the level of stearic acid [24]. Once the membrane matures (adulthood), we can have the exact perception of the real state of the membrane, therefore, its ability to capture serotonin depending on the molecular characteristics of platelets in cases of $\mathrm{MD}$ or $\mathrm{BD}$. The concept is that the higher the viscosity of the membrane, the receptors increase the serotonin uptake; the lower the viscosity of membrane, than less amounts of serotonin enters the receptors $[23,25,26]$. Obviously, this affects the initial therapy, regardless of any other factor, and accounts for the recognition, by the psychiatrists, of the possibility that the high diagnostic error between $\mathrm{MD}$ and $\mathrm{BD}$, at the onset of the pathology, can determine unpleasant consequences [2]. The children's platelet fatty acids profile has a very high concentration of stearic acid, and as a result, the children's platelet membranes are highly saturated with increased viscosity corresponding to a higher uptake of serotonin with respect to the MD condition $[23,25,26]$. The concept of cell membrane viscosity, especially that of the neuron and platelet, also responsible of the central government of that bio-molecular intracellular complex called interactome and of its influence on quantum chemical scale of the ion channels, is often missed in its involvement in many psychiatric conditions [11]. Under this evidence and according to the classification of the children over the SOM we hypothesize that it is very difficult to have a classic condition of Major Depression in children.

However the distribution of the children over the SOM has showed that independently from the characteristic of their platelet' membrane, they show molecular characteristics, similar to the adult subjects, with respect to Mood Disorders. Further, the relationship among the three fatty acids chosen by the SOM seems to group differently the children with Mood Disorders and suicide thoughts from the normal ones (Figure 9).

\section{Conclusion}

A mathematical model for the classification of the depressive disorders has shown that platelet membrane viscosity presents different characteristics in $\mathrm{MD}$ and $\mathrm{BD}$ and finds in $\mathrm{AP}, \mathrm{AL}, \mathrm{AA}$ the main elements of criticality [19,27-29].

We know that the $\mathrm{BD}$ is the psychiatric condition with a higher risk of suicide and it is likely that it is not possible to investigate and highlight the real risk without the use of biological markers [30]. Some risk factors have been identified as well as different ways to highlight biological markers of suicide have been tried [15,31-40]

Even with strong implications for plausibility, these attempts have not been successful, up to now, to identify classification tools that may allow early interventions for prevention.

We know that the SOM cannot be manipulated and it has a very high degree of diagnostic precision, so we can assume that the children investigated can correspond to the adults for the presence of Mood Disorders. However, in view of the fact that we have not subjected them to psychiatric evaluation for the complexity of the ethical reasons, we are aware that these issues need to be further explored so that it is possible to alert the psychiatrist in front of the not infrequently, dramatic, child's predisposition to suicide.

The index of membrane fluidity is stable in the same subject over time. A condition of greater or lesser clinical compensation corresponds to non-substantial variations of the viscosity and never allows a transition from a positive to a negative value or vice versa. Clinical improvement appears to correspond to an increase of the membrane $\mathrm{B} 2$ index, i.e. increasing the viscosity towards the normal one.

\section{References}

1. Cocchi M, Tonello L, Gabrielli F (2015) Molecular and quantum approach to psychopathology and consciousness. Ann Depress Anxiety 2: 1046.

2. Bowden CL (2001) Strategies to reduce misdiagnosis of bipolar depression. Psychiatr Serv 52: 51-55. 
3. Heidegger M (1997) Platons Lehre von der Wahrheit. Verlag Vittorio Klostermann, pp. 42.

4. Whitaker R (2010) Anatomy of an epidemic: magic bullets, psychiatric drugs, and the astonishing rise of mental illness in America. Crown Publishers, New York, USA.

5. Le-Niculescu H, Kurian SM, Yehyawi N, Dike C, Patel SD, et al. (2009) Identifying blood biomarkers for mood disorders using convergent functional genomics. Mol Psychiatry 14: 156-174.

6. Poulter MO, Du L, Weaver IC, Palkovits M, Faludi G, et al. (2008) GABAA receptor promoter hypermethylation in suicide brain: implications for the involvement of epigenetic processes. Biol Psychiaty 64: 645- 652.

7. Quilter CL, Gilbert CL, Oliver GL, Jafer O, Furlong RA, et al. (2008) Gene expression profiling in porcine maternal infanticide: A model for puerperal psychosis. Am J Med Genet Part B 147B: 1126-1137.

8. Cocchi M, Tonello L, Tsaluchidu S, Puri BK (2008) The use of artificial neural networks to study fatty acids in neuropsychiatric disorders. BMC Psychiatry 8: S1-S3.

9. Cocchi M, Tonello L (2010) Bio molecular considerations in major depression and ischemic cardiovascular disease. Cent Nerv Syst Agents Med Chem 10 97-107.

10. Cocchi M, Tonello L, Rasenick MM (2010) Human depression: a new approach in quantitative psychiatry. Ann Gen Psychiatry 9: 25.

11. Cocchi M, Gabrielli F, Tonello L, Pregnolato M (2010) The interactome hypothesis of depression. NeuroQuantology 4: 603-613.

12. Cocchi M, Tonello L, Gabrielli F, Pregnolato M (2011) Depression, osteoporosis, serotonin and cell membrane viscosity between biology and philosophical anthropology. Ann Gen Psychiatry 10: 9.

13. Colomba M, Gregorini A, Benedetti S (2012) Molecular changes in mood disorders results of the marche region special project. NeuroQuantology 10 : S1-S28.

14. Donati RJ, Dwivedi Y, Roberts RC, Conley RR, Pandey GN, et al. (2008) Postmortem brain tissue of depressed suicides reveals increased Gs alpha localization in lipid raft domains where it is less likely to activate adenylyl cyclase. J Neurosci 28: 3042-3050.

15. Hameroff SR, Penrose R (1996) Toward a science of consciousness. In Hameroff SR, Kaszniak A, Scott AC (Eds), The first tucson discussions and debates. MIT Press, Cambridge, UK, pp. 507-540.

16. Hagan S, Hameroff SR, Tuszynski JA (2002) Quantum computation in brain microtubules: Decoherence and biological feasibility. Physical Reviews E 65: 061901.

17. Flynn G, Alexander D, Harris A, Whitford T, Wong W, et al. (2008) Increased absolute magnitude of gamma synchrony in first-episode psychosis. Schizophr Res 105: 262-271.

18. Tonello L, Cocchi M (2010) The cell membrane: is it a bridge from psychiatry to quantum consciousness? NeuroQuantology 8: 54-60.

19. lida R, Takeyama N, lida N, Tanaka T (1991) Characterization of overt carnitine palmitoyltransferase in rat platelets; involvement of insulin on its regulation. Mol Cell Biochem 103: 23-30.

20. Kohonen T, Schroeder MR, Huang TS (2001) Self-organizing maps. SpringerVerlag New York Inc., Secaucus, NJ, USA

21. Kohonen T, Oja M, Kaski S, Somervuo P (1998) Self-organizing map. Neurocomputing 21: 113-122.

22. Kohonen T (1982) Self-organized formation of topologically correct feature maps. Biol Cybern 43: 59-69.

23. Cocchi M, Tonello L, Gabrielli F (2012) Considerations on blood platelets: a neuron's mirror for mood disorders? Open Journal of Blood Diseases 2: 22-29.
24. Cocchi M, Tonello L, Cappello G, Tarozzi G, Nabacino L, et al. (2008) Membrane platelet fatty acids: biochemical characterisation of the ischemic cardiovascular disease, characteristics of the paediatric age, through an artificial neural network interpretation. Pediatr Med Chir 30: 25-30.

25. Heron DS, Shinitzky M, Hershkowitz M, Samuel D (1980) Lipid fluidity markedly modulates the binding of serotonin to mouse brain membranes. Proc Natl Acad Sci U S A 77: 7463-7467.

26. Lee RE (1985) Membrane engineering to rejuvenate the ageing brain. Can Med Assoc J 132: 325-327

27. Cocchi M, Tonello L, De Lucia A, Amato P (2009) Platelet and brain fatty acids: a model for the classification of the animals? Part 1 . Int $\mathrm{J}$ Anthropol 24: 69-76.

28. Cocchi M, Tonello L, De Lucia A, Amato P (2009) Platelet and brain fatty acids: a model for the classification of the animals? Part 2 platelet and brain fatty acid transfer: hypothesis on arachidonic acid and its relationship to major depression. Int J Anthropol 24: 201-220.

29. Cocchi M, Sardi L, Tonello L, Martelli G (2016) Do Mood Disorders Play a Role on Pig Welfare? Ital J Anim Sci 8: 691-704.

30. Mathews DC, Richards EM, Niciu MJ, Ionescu DF, Rasimas JJ, et al. (2013) Neurobiological aspects of suicide and suicide attempts in bipolar disorder. Transl Neurosci 4: 203-216.

31. Undurraga J, Baldessarini RJ, Valenti M, Pacchiarotti I, Vieta E (2012) Suicidal risk factors in bipolar I and II disorder patients. J Clin Psychiatry 73: 778-782.

32. Bellivier F, Yon L, Luquiens A, Azorin JM, Bertsch J, et al. (2011) Suicidal attempts in bipolar disorder: results from an observational study (EMBLEM). Bipolar Disord 13: 377-386

33. Turecki G, Ernst C, Jollant F, Labonte B, Mechawar N (2012) The neurodevelopmental origins of suicidal behavior. Trends Neurosci 35: 14-23.

34. Pandey GN, Dwivedi Y (2012) Peripheral biomarkers for suicide. In: Dwivedi $Y(E d$.$) , The neurobiological basis of suicide. CRC Press, Boca Raton FL,$ USA, pp. 407-424

35. Pandey GN (2011) Neurobiology of adult and teenage suicide. Asian $\mathrm{J}$ Psychiatr 4: 2-13.

36. Mann JJ, Currier DM (2010) Stress, genetics and epigenetic effects on the neurobiology of suicidal behavior and depression. Eur Psychiatry 25: 268271.

37. Mann JJ (2003) Neurobiology of suicidal behaviour. Nat Rev Neurosci 4: 819 828.

38. Turecki G (2001) Suicidal behavior: is there a genetic predisposition? Bipolar Disord 3: 335-349.

39. Stanley M, Stanley B (1989) Biochemical studies in suicide victims: current findings and future implications. Suicide Life Threat Behav 19: 30-42.

40. Stanley M, Stanley B, Traskman-Bendz L, Mann JJ, Meyendorff E (1986) Neurochemical findings in suicide completers and suicide attempters. Suicide Life Threat Behav 16: 286-300.

41. Stahl SM, Woo DJ, Mefford IN, Berger PA, Ciaranello RD (1983) Hyperserotonemia and platelet serotonin uptake and release in schizophrenia and affective disorders. Am J Psychiatry 140: 26-30.

42. Thompson $P$ (1999) Platelet and erythrocyte membrane fluidity changes in alcohol-dependent patients undergoing acute withdrawal. Alcohol Alcohol 34: 349-354.

\section{Acknowledgements}

The authors thank the Marche Region (Italy) to have financially supported the Special Project "Molecular changes in mood disorders and their clinical-biochemical classification". 